\title{
Author Correction: Community-driven online initiatives have reshaped scientific engagement
}

James P. K. Armstrong (D), Irene de Lázaro (D), Natalie J. Kirkland (iD, Wilson Poon (D) and Shrey Sindhwani (i)

Correction to: Nature Reviews Materials https://doi.org/10.1038/s41578-021-00384-y, published online 08 October 2021.

In this article the affiliation details for author James P. K. Armstrong were incorrectly given as 'Department of Translational Health Sciences, University of Bristol, Bristol, UK' but should have been 'Department of Materials, Imperial College London, London, UK'. This has been corrected in the HTML and PDF versions of the manuscript.

https://doi.org/10.1038/s41578-021-00391-z I Published online 14 October 2021

() Springer Nature Limited 2021 